\title{
Erratum to: Application of USDA and SDBA Hamiltonians in calculating the excited states of odd-A magnesium isotopes
}

The Publishers

EDP Sciences, Società Italiana di Fisica and Springer-Verlag

Original article: Eur. Phys. J. Plus (2014) 129: 125, DOI: 10.1140/epjp/i2014-14125-0

Received: 19 June 2014

Published online: 30 June 2014 - (C) Società Italiana di Fisica / Springer-Verlag 2014

This paper has been published with an uncorrected version of table 1. We publish here below the correct version.

Table 1. Theoretical and new experimental energy for states with $J=(1 / 2 \text { to } 9 / 2)^{+}$in ${ }^{23} \mathrm{Mg}$ spectrum.

\begin{tabular}{cccccc}
\hline \multicolumn{2}{c|}{ References $[20,21]$} & \multicolumn{2}{c|}{ Reference $[22]$} & \multicolumn{2}{c}{ USDA } \\
\hline$J$ & $E(\mathrm{MeV})$ & $J$ & $E(\mathrm{MeV})$ & $J$ & $E(\mathrm{MeV})$ \\
\hline$(1 / 2 \text { to } 9 / 2)^{+}$ & 4.685 & $7 / 2^{+}$ & 4.680 & $7 / 2^{+}$ & 4.634 \\
& 5.691 & $(7 / 2)^{+}$ & 5.689 & $7 / 2^{+}$ & 5.363 \\
6.236 & $(9 / 2)^{+}$ & 6.238 & $9 / 2^{+}$ & 6.198 \\
& 6.507 & $(7 / 2)^{+}$ & 6.512 & $7 / 2^{+}$ & 6.575 \\
6.538 & $5 / 2^{+}$ & 6.573 & $5 / 2^{+}$ & 6.573 \\
& 7.493 & $9 / 2^{+}$ & 7.495 & $9 / 2^{+}$ & 7.483 \\
\hline
\end{tabular}

I.e., the value in the second row, last column, is 5.363 and not 5.961.

Moreover, on page 6, in the first sentence of the first paragraph, the wrong references are quoted. The correct version of the sentence is as follows:

"The states with $J=(19 / 2)^{+}$at energy $14.560 \mathrm{MeV}$ and $(21 / 2)^{+}$at energy $14.130 \mathrm{MeV}$ found in refs. [20,21] do not appear in fig. 2."

The Publishers regret this mistake and apologize for any inconvenience caused. 